\title{
Weldability of the superalloys Haynes 188 and Hastelloy $X$ by Nd:YAG
}

\author{
Jérémie Graneix ${ }^{1}$, Jean-Denis Beguin ${ }^{1}$, François Pardheillan ${ }^{2}$, Joël Alexis ${ }^{1, a}$, and Talal Masri ${ }^{1}$ \\ ${ }^{1}$ Université de Toulouse, LGP, ENIT/INPT, 47 avenue d'Azereix, BP. 1629, 65016 Tarbes Cedex, France \\ ${ }^{2}$ Exameca, 64121 Serres Castet, France
}

\begin{abstract}
The requirements for welded aircraft parts have become increasingly severe, especially in terms of the reproducibility of the geometry and metallurgical grade of the weld bead. Laser welding is a viable method of assembly to meet these new demands, because of automation, to replace the manual TIG welding process. The purpose of this study is to determine the weldability of Hastelloy X and Haynes 188 alloys by the butt welding process with a Nd:YAG laser. To identify the influential parameters of the welding process (laser power, feed rate, focal diameter and flow of gas) while streamlining testing, an experimental design was established with the CORICO software using the graphic correlation method. The position of the focal point was fixed at 1/3 of the thickness of the sheet. The gas flow rate and the power of the beam have a major effect on the mechanical properties and geometry of the weld. The strength of the weld is comparable to that of the base metal. However, there is a significant decrease in the elongation at break of approximately $30 \%$. The first observations of the cross section of the weld by scanning electron microscopy coupled with EBSD analysis show a molten zone presenting dendritic large grains compared to the equiaxed grains of the base metals without a heat affected zone.
\end{abstract}

\section{Introduction}

Solid-solution-strengthened alloys Haynes 188 and Hastelloy $\mathrm{X}$ have good oxidation resistance, good mechanical properties at high temperature and a significant formability, sine qua criteria for the choice of materials for the production of turbojet combustion chambers, which is part of this study [1].

The requirements for welded aeronautical parts have become increasingly severe, especially in terms of the reproducibility of the geometry and metallurgical-grade fillet weld. Laser welding is a viable method of assembly to meet these new demands by automation and to replace manual TIG welding. Given the multitude of input parameters and the complexity of the phenomena involved, the implementation of an experimental design approach is required [2,3]. The purpose of this study is to determine the field of the homogeneous weldability of alloys Hastelloy $\mathrm{X}$ and Haynes 188 by welding with a $\mathrm{Nd}$ :YAG laser and to determine the relationships among the parameters, mechanical properties and microstructure. The effects of the process parameters, such as welding power, welding speed, focal beam diameter and the flow rate of the inert gas, on the geometrical shape of fillet welds are studied.
Table 1. Chemical composition of the Hastellloy X (wt\%).

\begin{tabular}{lcccccccc}
\hline $\mathbf{N i}$ & $\mathbf{C r}$ & $\mathbf{C o}$ & $\mathbf{M o}$ & $\mathbf{W}$ & $\mathbf{F e}$ & $\mathbf{M n}$ & $\mathbf{S i}$ & $\mathbf{C}$ \\
$\mathrm{Bal}$ & 22.1 & 1.38 & 9.0 & 0.45 & 18.7 & 0.66 & 0.35 & 0.07 \\
\hline
\end{tabular}

Table 2. Chemical composition of the Haynes 188 (wt\%).

\begin{tabular}{lcccccccc}
\hline $\mathbf{N i}$ & $\mathbf{C r}$ & $\mathbf{C o}$ & $\mathbf{L a}$ & $\mathbf{W}$ & $\mathbf{F e}$ & $\mathbf{M n}$ & $\mathbf{S i}$ & $\mathbf{C}$ \\
22.0 & 22.0 & Bal & 0.03 & 14.0 & 3.0 & 1.25 & 0.35 & 0.1 \\
\hline
\end{tabular}

\section{Base metals and experimental process}

\subsection{Base metals}

The alloys studied are the nickel-chromium-molybdenum alloy Hastelloy $\mathrm{X}$ and the cobalt-nickel-chromiumtungsten alloy Haynes 188, whose compositions are given, respectively, in Table 1 and Table 2 . The sheet metals are in the annealed condition: they were heat treated between $1150^{\circ} \mathrm{C}$ and $1175^{\circ} \mathrm{C}$ and cooled rapidly. Treatment and cooling were conducted under a protective atmosphere [2]. Their thickness is $1.2 \mathrm{~mm}$.

The microstructures have been studied from observations by optical microscopy and scanning electron microscopy (FEG-SEM JEOL 7000F) coupled with EBSD analysis (OXFORD Nordlys Fast camera). The microstructure consists of equiaxed grains of average size between 100 and $150 \mu \mathrm{m}$ for Hastelloy X and between 70 and $100 \mu \mathrm{m}$ for the Haynes 188 regardless of the plane plate studied (Fig. 1). Neither plate shows texture.

The tensile mechanical properties in different directions in the plane RD-LT have been determined for the

\footnotetext{
${ }^{a}$ Corresponding author: joel.alexis@enit.fr
}

This is an Open Access article distributed under the terms of the Creative Commons Attribution License 4.0, which permits unrestricted use, distribution, and reproduction in any medium, provided the original work is properly cited. 
Hastelloy X

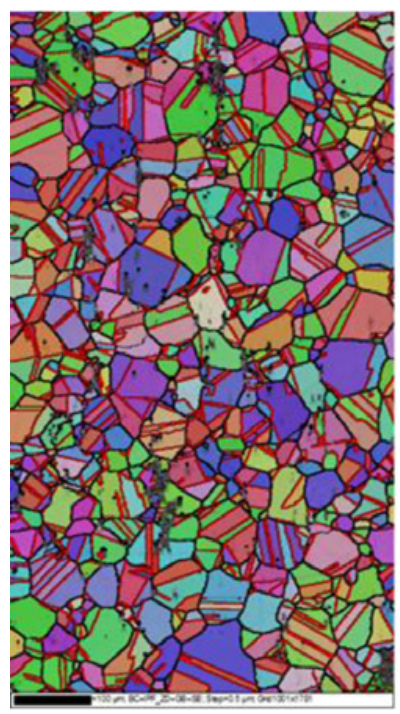

Haynes 188

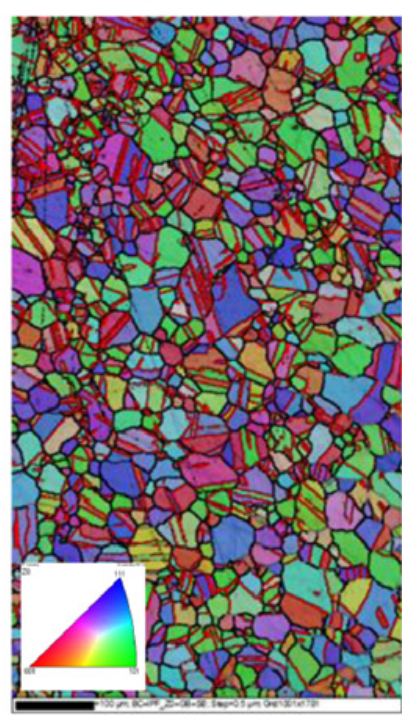

Figure 1. Inverse pole figure orientation map (IPF Z0) of the base metal Hastelloy X and the base metal Haynes 188.

Table 3. Mechanical properties of Hastelloy X (Young's modulus, yield strength, ultimate tensile strength, elongation at rupture, Vickers hardness).

\begin{tabular}{l|clllc}
\hline & $E(G P a)$ & $Y S(M P a)$ & $U T S(M P a)$ & $\varepsilon_{r}(\%)$ & $H V_{0.5}$ \\
\hline $0^{\circ}$ & $208 \pm 10$ & $446 \pm 3$ & $799 \pm 2$ & $55 \pm 2$ & $230 \pm 10$ \\
$45^{\circ}$ & $211 \pm 15$ & $446 \pm 11$ & $793 \pm 11$ & $53 \pm 2$ & \\
$90^{\circ}$ & $190 \pm 20$ & $456 \pm 5$ & $806 \pm 5$ & $58 \pm 8$ & \\
\hline
\end{tabular}

Table 4. Mechanical properties of Haynes 188.

\begin{tabular}{l|ccccc}
\hline & $E(G P a)$ & $Y S(M P a)$ & $U T S(M P a)$ & $\varepsilon_{r}(\%)$ & $H V_{0.5}$ \\
\hline $0^{\circ}$ & $188 \pm 1$ & $524 \pm 10$ & $1057 \pm 14$ & $76 \pm 2$ & $275 \pm 11$ \\
$45^{\circ}$ & $200 \pm 1$ & $516 \pm 4$ & $1048 \pm 3$ & $71 \pm 2$ & \\
$90^{\circ}$ & $201 \pm 1$ & $527 \pm 8$ & $1055 \pm 7$ & $72 \pm 2$ & \\
\hline
\end{tabular}

base alloys. No anisotropy of the mechanical properties for the two metal sheets is demonstrated, confirming previous microstructural observations.

\subsection{Experimental process of welding}

The samples were cut and butt welded with a TRUMPH TruLaser Cell 3000 machine. The laser source is a Nd:YAG TruDisk with a maximum continuous power of $3.3 \mathrm{~kW}$, equipped with a special optical fibre comprising a $100 \mu \mathrm{m}$ core fibre and a $400 \mu \mathrm{m}$ coaxial fibre.

Two laser parameters are particularly important for welding: the power density of the laser beam and the interaction time. They determine how much energy per area and per unit of time is introduced into the workpiece process. The power density can be controlled by changing the laser power and size of the focus. The interaction time can be adjusted for spot work by changing the irradiation time or by altering the feed rate. To identify the influential parameters of the welding process while streamlining testing, an experimental design was established with the CORICO software [4] to understand the possibilities
Table 5. Design matrix defined by the CORICO software.

\begin{tabular}{lccccc}
\hline & $\begin{array}{c}\text { Power } \\
(\mathbf{w})\end{array}$ & $\begin{array}{c}\text { Speed } \\
\left(\mathbf{m . m i n}^{-1}\right)\end{array}$ & $\begin{array}{c}\boldsymbol{\emptyset}_{\text {SF }} \\
(\boldsymbol{\mu} \mathbf{m})\end{array}$ & $\begin{array}{c}\boldsymbol{\emptyset}_{\mathbf{L F}} \\
(\mu \mathbf{m})\end{array}$ & $\left.\begin{array}{c}\text { Gas flow } \\
(\mathbf{t . m i n}\end{array} \mathbf{1}^{\mathbf{1}}\right)$ \\
\hline S1 & 1000 & 6.25 & 305 & 375 & 25 \\
\hline S2 & 1500 & 1.00 & 110 & 450 & 10 \\
\hline S3 & 2500 & 8.00 & 175 & 525 & 40 \\
\hline S4 & 2500 & 4.50 & 240 & 600 & 32 \\
\hline S5 & 1500 & 8.00 & 240 & 600 & 32 \\
\hline S6 & 1000 & 6.25 & 175 & 525 & 25 \\
\hline S7 & 1500 & 1.00 & 305 & 675 & 32 \\
\hline S8 & 2000 & 6.25 & 175 & 525 & 17 \\
\hline S9 & 2000 & 8.00 & 305 & 675 & 17 \\
\hline S10 & 2000 & 2.75 & 305 & 675 & 40 \\
\hline S11 & 1000 & 6.25 & 240 & 600 & 32 \\
\hline S12 & 2000 & 4.50 & 305 & 675 & 10 \\
\hline S13 & 2000 & 6.25 & 370 & 750 & 40 \\
\hline S14 & 1500 & 4.50 & 370 & 750 & 17 \\
\hline S15 & 1000 & 2.75 & 240 & 600 & 32 \\
\hline S16 & 2500 & 2.75 & 270 & 750 & 17 \\
\hline S17 & 1500 & 6.25 & 110 & 450 & 40 \\
\hline S18 & 500 & 2.75 & 175 & 525 & 25 \\
\hline S19 & 2500 & 1.00 & 240 & 600 & 25 \\
\hline S20 & 500 & 4.50 & 205 & 675 & 10 \\
\hline S21 & 1000 & 4.50 & 370 & 750 & 17 \\
\hline S22 & 500 & 8.00 & 110 & 450 & 25 \\
\hline S23 & 2000 & 2.75 & 175 & 525 & 32 \\
\hline S24 & 1500 & 4.50 & 240 & 600 & 25 \\
\hline S25 & 500 & 8.00 & 110 & 450 & 10 \\
\hline S26 & 500 & 1.00 & 370 & 750 & 10 \\
\hline S27 & 500 & 1.00 & 110 & 450 & 40 \\
\hline S28 & 2500 & 1.00 & 110 & 450 & 10 \\
\hline S29 & 2500 & 8.00 & 370 & 750 & 40 \\
\hline S30 & 500 & 1.00 & 110 & 450 & 10 \\
\hline & & & & & \\
\hline
\end{tabular}

offered by this new technology. Four parameters were selected for this study: the laser power, the welding speed, the focal diameter and the gas flow (Table 5). The laser beam can be carried by the core of the fibre, and the focal diameter is considered small (SF). It can also be carried by the periphery of the fibre, which corresponds to a large focal diameter (LF).

During the laser welding operation, the specimens were clamped rigidly by a fixture that was designed and manufactured for this study to align the laser beam with the butt joint and avoid any thermal distortion.

\subsection{Experimental characterisation}

For each welding condition, samples were taken for metallographic observations and mechanical tests. Before being observed under a Leica Wild M420 stereo microscope at a magnification of 50, samples were mounted in a phenolic thermosetting resin, grounded and polished. The microstructure was revealed with an etching solution $\left(96 \% \mathrm{HCl}, 4 \% \mathrm{H}_{2} \mathrm{O}_{2}\right)$.

To validate the weldability of these alloys, the dimensions of the cord section were measured and compared to standard specifications described in EN ISO 6947 (Fig. 2). Microtensile tests were also performed on each condition to obtain the ultimate tensile stress in the normal direction to the weld. 

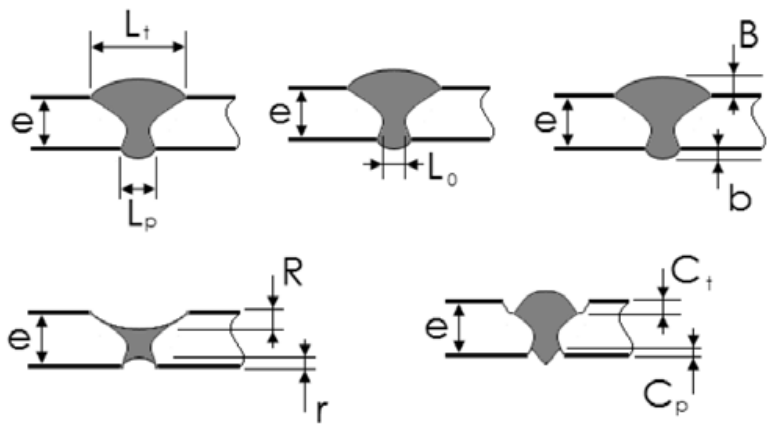

Figure 2. Geometry conditions with respect to welding norm EN ISO 6947.

The position of the focal point relative to the surface of the sheet has not been considered as a variable parameter. Indeed, much research in this area showed a penetration at a maximum focal length of $1 / 3$ of the sheet thickness relative to the surface, regardless of the focal diameter and the feed speed [3].

This study was conducted in several stages with CORICO software: a preliminary study was conducted to determine the limits of weldability defined from the geometric criteria of a fillet weld. A second study clarified the weldability, taking into account the mechanical properties of the fillet weld, and highlights the influence of each parameter on the welding quality of the welded joint.

\section{Experimental results and discussion}

\subsection{Determining the weldability for both alloys}

The weldability was defined for each alloy from 30 homogeneous welded specimens. Figure 3 shows, respectively, the fields of weldability of these two alloys according to the power, the welding speed and the focal diameter. The conditions represented by circles are those where the weld is penetrating and respects the geometric criteria of the standard. The triangular cursor indicates that the weld is only penetrating, and the square sliders represent the conditions for which the weld is not penetrating. Analysis of the various maps of Fig. 4 suggests that the power parameter is a parameter of the first order. The weldability becomes relevant for powers between $1500 \mathrm{~W}$ and $2500 \mathrm{~W}$. For a power of $2000 \mathrm{~W}$, the weldability is most important for both alloys.

Iconographic correlation of the experimental design performed by the CORICO software (Fig. 4) confirmed that the most influential factor on the geometry and mechanical properties was the power. Other factors, such as the speed of the welding head and the flow of the gas, also affect the response but to a smaller degree. An increase in the power results in an increase of all of the geometrical dimensions of the bead [5]. Conversely, increases of the focal diameter or the speed cause a decrease of the same geometrical parameters. The gas flow has a significant influence on the protection against oxidation during welding. The sphere iconographic relationship also shows that the shrinkage groove parameters $\mathrm{Ct}$ and $\mathrm{Cp}$
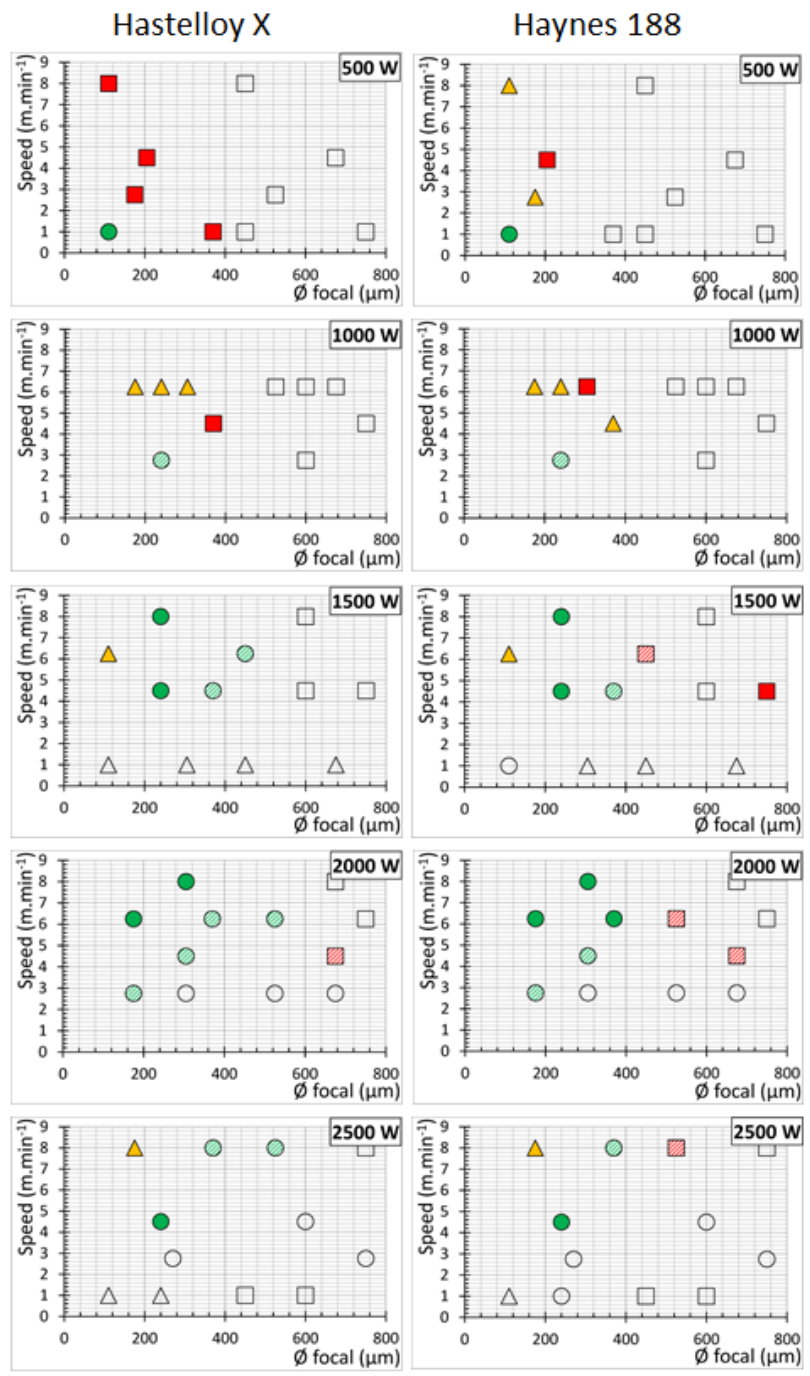

Figure 3. Weldability field of the Hastelloy $\mathrm{X}$ and the Haynes 188 alloys.



Figure 4. Iconographic relations graphic.

cannot be obtained directly by acting on the process parameters.

For each response $\mathrm{Y}$, a regression equation is created from the iconographic correlations as:

$$
Y_{i}=b_{0}+b_{1} X_{1 i}+\ldots b_{p} X_{p i}+u_{i} .
$$

Constants $b_{p}$ are the coefficients of the partial regression model, the constant $u_{i}$ is the random term and the regressors $X_{p i}$ are determined by factors or interactions logical correlated to the best answer. From the regression 
Table 6. Optimised parameters determined by the software CORICO for homogeneous welding Hastelloy $\mathrm{X}$ and Haynes 188.

\begin{tabular}{l|cccc}
\hline & \multicolumn{3}{|c}{ Hastelloy X } & \multicolumn{3}{c}{ Haynes 188 } \\
\hline & SF & LF & SF & LF \\
Power $(\mathrm{W})$ & 1571 & 2430 & 2097 & 2353 \\
Speed $\left(\mathrm{m} . \mathrm{min}^{-1}\right)$ & 7.65 & 3.17 & 4.12 & 1.39 \\
Gas flow $\left(\mathrm{L} \cdot \mathrm{min}^{-1}\right)$ & 350 & 518 & 370 & 750 \\
$\varnothing$ focal $(\mu \mathrm{m})$ & 40 & 39 & 33 & 40 \\
\hline
\end{tabular}

Table 7. Comparison of the different geometric criteria of the fillet weld, as determined by the CORICO software and measured by optical microscopy.

\begin{tabular}{c|lcccc}
\hline & & \multicolumn{3}{c}{ Hastelloy $X$} & \multicolumn{2}{c}{ Haynes 188} \\
\hline \multirow{4}{*}{$\mathrm{L}_{\mathrm{t}}$} & & $\mathrm{SF}$ & $\mathrm{LF}$ & $\mathrm{SF}$ & $\mathrm{LF}$ \\
& & & \\
$\mathrm{L}_{\mathrm{p}}$ & calculated & $\mathbf{1 . 1 7}$ & $\mathbf{1 . 1 0}$ & $\mathbf{0 . 8 0}$ & $\mathbf{1 . 6 4}$ \\
& measured & 0.80 & 1.47 & 1.13 & 1.81 \\
$\mathrm{~L}_{0}$ & calculated & $\mathbf{1 . 0 2}$ & $\mathbf{1 . 3 2}$ & $\mathbf{1 . 0 7}$ & $\mathbf{1 . 3 6}$ \\
& measured & 0.50 & 1.31 & 0.84 & 1.66 \\
$\mathrm{~B}$ & calculated & $\mathbf{0 . 8 9}$ & $\mathbf{0 . 9 9}$ & $\mathbf{0 . 4 3}$ & $\mathbf{1 . 3 8}$ \\
$\mathrm{B}$ & measured & 0.33 & 0.73 & 0.52 & 1.49 \\
& calculated & $\mathbf{0 . 0 2}$ & $\mathbf{0 . 0 6}$ & $>\mathbf{0 . 0 1}$ & $\mathbf{0 . 0 2}$ \\
$\mathrm{b}$ & measured & 0 & 0.03 & 0 & 0.02 \\
& calculated & $\mathbf{0 . 0 5}$ & $\mathbf{0 . 0 8}$ & $\mathbf{0 . 0 4}$ & $\mathbf{0 . 0 3}$ \\
$\mathrm{R}$ & measured & 0 & 0.03 & 0.06 & 0.04 \\
$\mathrm{R}$ & calculated & $\mathbf{0 . 0 5}$ & $\mathbf{0 . 0 1}$ & $>\mathbf{0 . 0 1}$ & $>\mathbf{0 . 0 1}$ \\
$\mathrm{r}$ & measured & 0.04 & 0 & 0 & 0 \\
& calculated & $>\mathbf{0 . 0 1}$ & $>\mathbf{0 . 0 1}$ & $>\mathbf{0 . 0 1}$ & $\mathbf{0}$ \\
$\mathrm{C}_{\mathrm{t}}$ & measured & 0 & 0 & 0 & 0 \\
& calculated & $\mathbf{0 . 0 2}$ & $>\mathbf{0 . 0 1}$ & $\mathbf{0 . 0 1}$ & $>\mathbf{0 . 0 1}$ \\
$\mathrm{C}_{\mathrm{p}}$ & measured & 0 & 0 & 0 & 0 \\
& calculated & $\mathbf{0}$ & $>\mathbf{0 . 0 1}$ & $>\mathbf{0 . 0 1}$ & $\mathbf{0}$ \\
& measured & 0 & 0 & 0 & 0 \\
\hline
\end{tabular}

equations, optimisation factors was performed using the software CORICO implementing a random Monte Carlo based on the desirability of different answers. The optimum parameters are summarised in Table 6 for the small and large focal lengths for both homogeneous welding.

The dimensions of the fillet welds with these optimised parameters were characterised by optical microscopy on cross-sections cut along the plane LT-ST to compare the geometry of the beads obtained to that provided by the software CORICO (Table 7). The dimensions of the fillet weld were consistent with the values expected by the software despite greater dispersion for the fillet weld with a smaller focal. All welds obtained with the welding parameters determined by the software meet the criteria of the standard. The microstructure and mechanical properties of these optimised fillet welds were characterised to better understand the influence of the welding parameters.

\subsection{Microstructure of optimised welds}

The fusion zone shape and final solidification structure of these two alloys were evaluated as a function of the laser parameters. The shapes of the weld beads optimised in cross section are shown in Fig. 5. A typical form of a keyhole welding mode is observed for the butt weld



Figure 5. Metallographic observations of welds obtained with the optimal welding parameters.


Figure 6. Inverse pole figure orientation map (IPF Z0) of the butt weld obtained with a small focal (a) Hastelloy X, (c) Haynes 188 and with large focal (b) Hastelloy X and (d) Haynes 188.

obtained with a small focal, and an X-shaped weld is more representative of a conduction welding method obtained with a large focal. The conduction mode is characterised by low penetration welds. The weld depth is determined by a combination of heat conduction and convection of the liquid in the solder bath. In contrast, the mode called keyhole, wherein evaporation and ejection of metal occurs, achieves substantial penetration depths.

Regardless of the welding mode, normal columnar dendritic grains are observed in terms of solidification from the fusion boundary to the heat affected zone. The heat affected zone is not visible. B.S. Yilbas showed the same result for $\mathrm{CO}_{2}$ laser welding of Haynes 188 alloy [6]. The liquid is generally solidified epitaxially with respect to the substrate. The solid needs not germinate solidification from unmelted grains (Fig. 6).

\subsection{Mechanical properties of the optimised fillet weld}

Transverse tensile tests were performed on the welded joints. Figure 7 shows the different stress-strain curves obtained for the welded joints and base metals. Welded joints have a different mechanical behaviour than the base materials. Analyses of the stress-strain curves were performed to determine the transverse ultimate tensile strength, yield strength and elongation at rupture (Table 8). 


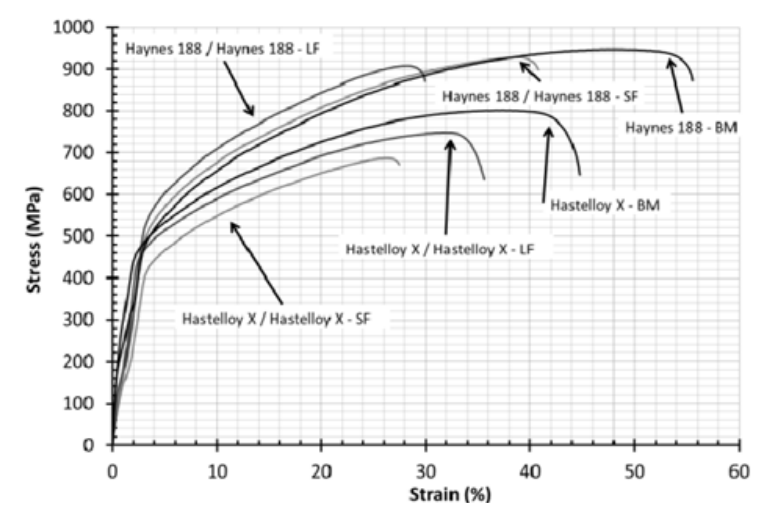

Figure 7. Stress-strain curves obtained for the welded joints loaded in the transverse direction and for the base metals.
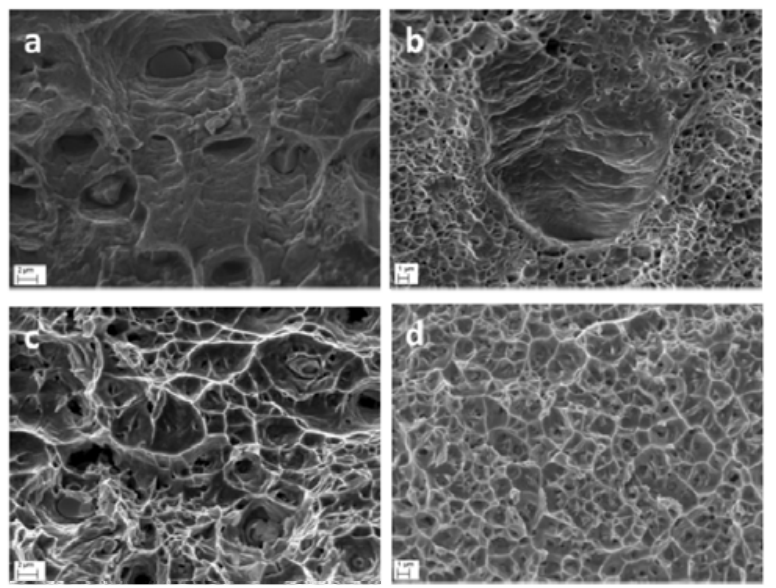

Figure 8. Fracture surfaces observed by scanning electron microscopy (a) Hastelloy X, (b) Hastelloy X-Hastelloy X butt welded, (c) Haynes 188 and (d) Haynes 188-Haynes 188 butt welded.

Table 8. Mechanical properties of the optimised weld bead.

\begin{tabular}{l|cccc}
\hline & $\varphi_{\text {focal }}$ & $\begin{array}{c}Y S \\
(M P a)\end{array}$ & $\begin{array}{c}\text { UTS } \\
(M P a)\end{array}$ & $\begin{array}{c}E \\
(\%)\end{array}$ \\
\hline Hastelloy X / Hastelloy X & SF & 436 & 687 & 22 \\
Hastelloy X / Hastelloy X & LF & 451 & 748 & 32 \\
Hastelloy X - weld bead & LF & 364 & 637 & 20 \\
Haynes 188 / Haynes 188 & SF & 515 & 927 & 35 \\
Haynes 188 / Haynes 188 & LF & 583 & 908 & 24 \\
Haynes 188 - weld bead & LF & 437 & 749 & 24 \\
\hline
\end{tabular}

The yield strength of the welded specimens is comparable to those of the respective base materials (BM). In contrast, the ultimate tensile strength and elongation at rupture of the butt welds are inferior to those of the base materials.

The rupture zone of the specimens was still localised in the weld, regardless of the focal diameter and welded base materials. The ruptures observed by scanning electron microscopy are shown in Fig. 8. The fracture surface of base metals Hastelloy X or Haynes 188 exhibit predominately dimpled rupture features without any preferential fracture paths. The dimples have various shapes and sizes (Figs. 8a and b).

To complete these tests and analyses, tensile tests in the longitudinal direction of the weld were performed. The

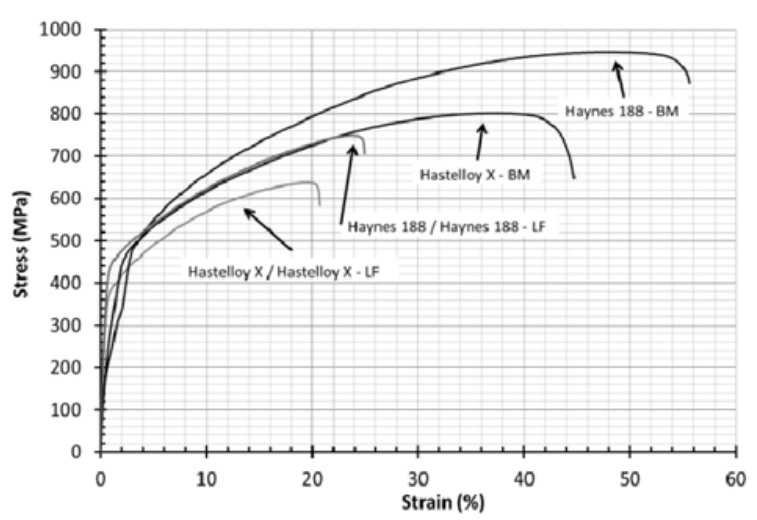

Figure 9. Stress-strain curves obtained for the welded joints loaded in the welding direction and for the base metals.

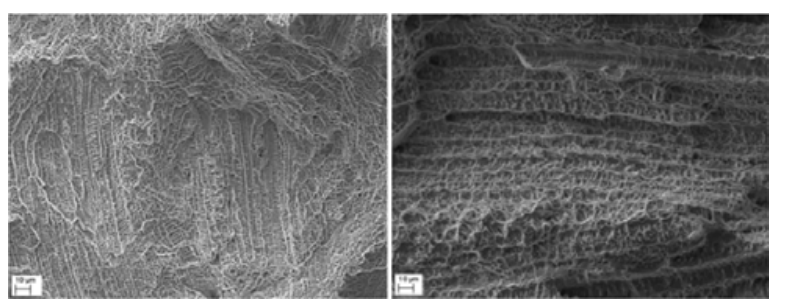

Figure 10. Fracture surfaces observed by scanning electron microscopy (a) Hastelloy X-Hastelloy X butt welded, (d) Haynes 188-Haynes 188 butt welded.

results of these tests are shown in Fig. 9. The mechanical properties of the melt zone are lower than those of the base materials. In contrast, the ductility of the molten zone is comparable to that determined in the transverse tensile testing. This low ductility can be explained by the observations of the fracture surface of the tensile samples (Fig. 10). The appearance of dendritic patterns on the weld fracture surface indicates that the fracture had taken place preferentially along the interdendritic regions. Some minor spherical particles were detected by EDS as enriched in Mo and W for the Hastelloy X and W for the Haynes 188 alloy. The fracture process is an easier way of providing favourable sites for excessive microvoid initiation and growth of microscopic cracks. It results in lower tensile strength and elongation.

\section{Conclusion}

The weldability of Hastelloy X and Haynes 188 alloys was defined, based on the welding parameters, such as the laser power, the speed, the focal diameter and the gas flow. The most influential parameters were the laser power and the focal diameter. The predicted values from the experimental design given by the CORICO software with small or large focal diameters are similar to the experimental values, with greater dispersion for the small focal diameter.

The yield strength of the welded joint is similar to that of the base metal, whereas the tensile strength and ductility are reduced. This loss of the properties can be explained by the dendrite orientation in the molten zone, with respect to the tensile stress solicitation. Further analyses of the carbon content and, more specifically, of the state of 
precipitation in the weld are planned in order to understand their mechanical behaviour.

\section{References}

[1] Hastelloy X alloy, Haynes international report $H$ 3009C, 1-16, (1997)

[2] K.Y. Benyounis, A.G. Olabi, M.S.J. Hashmi, Optic Laser Tech, 40, 76-87 (2008)
[3] M. Ghoreishi, Int J Adv Manuf Technol, 29, 70-78 (2006)

[4] http://www.coryent.com

[5] M. Moradi, M. Ghoreishi, Int J Adv Manuf Technol, 55, 205-215 (2011)

[6] B.S. Yilbas, S. Akthar, Int J Adv Manuf Technol, 56, 115-124 (2011) 